\title{
SEFARDISMO AFRICANO NO SÉCULO XVII
}

MARK, Peter \& HORTA, José da Silva. The Forgotten Diaspora: Jewish Communinities in West Africa and the Making of the Atlantic World. Nova York: Cambridge University Press, 2011. 262 p.

A diáspora esquecida é o título, em português, deste livro de Peter Mark e José da Silva Horta. O primeiro é professor de História da Arte na Wesleyan University (Connecticut), dedicado aos estudos sobre identidades culturais na Senegâmbia no período pré-colonial que, na linguagem dos africanistas, se refere ao período da expansão marítima europeia entre os séculos XVI e XVIII. José da Silva Horta é professor na Universidade de Lisboa, onde atua nas áreas de História da África e História da Expansão e, como seu colega Mark, dedica-se aos estudos sobre a os contatos econômicos e culturais entre os portugueses e os povos da "Guiné do Cabo Verde", uma estreita faixa litorânea entre o Cabo Verde e o rio Saloum, ao norte da Gâmbia atual.

O tema do livro é muito original, sob todos os pontos de vista, porque se arrisca a estudar as comunidades judaicas de origem ibérica, com des- taque para a portuguesa, em região de grande importância para o comércio atlântico como era a Senegâmbia. Comércio não só de escravos, mas de outras mercadorias valiosas, a exemplo do marfim e das peles.

O título do livro é, portanto, exato, pois esta diáspora sefardita estava mesmo esquecida, para não dizer desconhecida, entre os estudiosos das comunidades sefarditas espalhadas pelo mundo, a partir dos séculos XV e XVI. Bastaria citar, para comproválo, o grande livro de Jonathan Israel, Diasporas Within a Diaspora (2002), composto de 18 estudos sobre as comunidades sefarditas em regiões de vários continentes: nas cidades italianas, como Veneza e Ferrara; nas cidades do império turco-otomano, como Salonica e Esmirna; na América espanhola, desde o Rio da Prata à Nova Espanha (México); no Brasil holandês; na França, a exemplo de Bordeaux; no norte europeu, com 
destaque para Londres, Hamburgo e, principalmente, Amsterdã. Jonathan Israel não deixa a África de lado, pois dedica um estudo à importante comunidade sefardita estabelecida no Marrocos. Mas é o único caso africano estudado no livro.

A presença de cristãos-novos ou de judeus assumidos na África subsaariana estava carente, sem dúvida, de um estudo monográfico. Até o livro de Mark e Horta, nosso conhecimento se limitava a informações pontuais e difusas. O livro de Alberto da Costa e Silva, A manilha e o libambo (2007), para citar um africanista brasileiro, oferece boas informações sobre o papel dos sefarditas de origem portuguesa no tráfico africano de escravos. O mesmo vale para o clássico Os holandeses no Brasil e na costa africana, de Klaas Ratelband, traduzida para o português somente em 2003, com revisão crítica do historiador angolano Carlos Pacheco.

Nos dois livros citados, à guisa de exemplo, as informações sobre a presença dos cristãos-novos e judeus portugueses, embora preciosas, limitam-se a indicar a participação deles no tráfico de escravos e suas importantes conexões com alguns centros nevrálgicos do capitalismo comercial na Época Moderna: as ligações com Lisboa, Madri, Sevilha, Amsterdã, sem falar nos portos coloniais das Américas portuguesa (Recife, Salvador, Rio de Janeiro) e espanhola (Vera Cruz, Lima, Cartagena, Buenos Aires). A elasticidade das redes comerciais sefarditas, espalhadas pelos sete mares e pelos quatro cantos do mundo já é assunto bem estudado e conhecido. Seu papel na configuração dos negócios marítimos a partir do século XVI também já foi salientado, inclusive insinuado (não mais que isso) por Fernand Braudel, na sua obra-prima, O Mediterrâneo e o mundo mediterrânico na época de Filipe II (1949).

Nenhum estudo, porém, se dedicou a iluminar as comunidades sefarditas da África sub-saariana nesta época. Reside nisto, portanto, o primeiro grande mérito da obra de Mark e Horta. Uma obra que oferece conhecimento novo, lastreada em fontes mal conhecidas ou inéditas. Esta a grande contribuição de qualquer livro de história, muito mais do que em tentar provar teorias ou inventar conceitos.

Nossos autores não descuidam, porém, das armadilhas conceituais ou vocabulares inerentes a qualquer estudo historiográfico. Longe disso, a começar pelos conceitos-chave de $\mathrm{Co}$ munidade e diáspora. $\mathrm{O}$ primeiro referenciado ao grupo específico dos sefarditas em termos de identidade sociocultural, crenças e relações parentais. $\mathrm{O}$ segundo relacionado à dispersão de indivíduos ou famílias pelos vários continentes do globo, em parte por causa da perseguição das inquisições ibéricas contra os conversos, em parte motivada pelo alargamento das oportunidades econômicas que a expansão comercial alinhava no horizonte. Os sefarditas integrariam, assim, uma "comunidade moral", 
alicerçada em uma trading diaspora, conceito originalmente proposto por Abner Cohen em Cultural Strategies in the Organization of Trading Diasporas (1971).

A necessidade de definições vocabulares vai além das noções de comunidade e diáspora. Isto porque falar em sefarditas é dizer muito pouco e os autores estão cientes disso. $\mathrm{O}$ sefardismo, vertente ibérica do judaísmo europeu, conheceu mutações importantes a partir do século XV. Na Espanha isto ocorreu desde as conversões "voluntárias", no final do século XIV, passando pela criação do Santo Ofício, em 1478, e culminando com a expulsão dos judeus pelos Reis Católicos, em 1492. Em Portugal, onde nunca houve "tradição marrana" até o final do século XV, o processo teve início em 1496, com o decreto de conversão forçada de d. Manuel, complementado pelo estabelecimento da Inquisição, em 1536. O descompasso entre Espanha e Portugal no tocante à cronologia das perseguições aos judeus, aos movimentos de conversão (espontânea ou forçada) e à implantação dos respectivos tribunais do Santo Ofício, teve papel decisivo na configuração do sefardismo, entre os séculos XV e XVII, com forte repercussão nas diásporas.

Além disso, cristãos-novos, criptojudeus e judeus não eram sinônimos. O cristão-novo, ou converso, tanto podia acalentar, no foro íntimo, a sua ancestralidade judaica, e mesmo praticar certos ritos "mosaicos", como integrar-se, de peito aberto, no mundo católico. Uns se mantiveram apegados à "lei de Moisés", outros buscaram a "lei de Cristo" e até ingressaram no clero. O criptojudeu, por sua vez, era aquele que, não obstante convertido ao catolicismo, mantinha-se apegado ao judaísmo, mesmo se restrito ao âmbito doméstico, limitado a guardar as festas judaicas, os ritos funerários e os tabus dietéticos. Criptojudeu é o que, na linguagem inquisitorial, caracterizava o judaizante, suspeito de cometer a heresia judaica. Enfim, judeu, nesse contexto, é o cristão-novo apóstata, o que renega o catolicismo, buscando terras onde o judaísmo é tolerado. Trata-se aqui do judeu público, sinônimo do cristão-novo renegado. A "comunidade moral" da trading diáspora era, portanto, heterogênea em sua composição, por assim dizer, antropológica. Isto vale para Europa, Oriente, Américas, Áfricas.

O livro de Mark e Horta se concentra, como disse, em uma região específica da costa ocidental africana, a Senegâmbia, ou Petite Côte, como a chamariam os franceses no século XIX, em particular os portos de Rufisque, de Porto d'Ale e de Joala. Os três portos pertenciam a reinos autônomos que se haviam desmembrado do Império Jalofo, entre o meado do século XVI e o início do XVII. Englobavam populações dos grupos jalofo, fulani ou jola, serere e mandinga. Rufisque, chamado pelos portugueses de "Rio Fresco", localizado na península de Cabo Verde, pertencia ao reino de Cayor. Porto 
d'Ale, ao sul de Rufisque, estava sob controle do rei de Bawol. Joala, enfim, situada à sudoeste de Dacar, era governado pelo soberano de Sine ou Siin. O litoral senegalês havia sido parcialmente islamizado desde o século XI, com a expansão almorávida. As elites dirigentes daqueles reinos, no limiar da expansão europeia, eram seguramente muçulmanas.

As fontes inquisitoriais são a base documental do livro, pois contêm denúncias, processos e outros documentos relacionados à vida de cristãosnovos ou judeus portugueses residentes naqueles portos. Mark e Horta descobriram papéis do Santo Ofício até então inexplorados pelos estudiosos do tribunal português. Mas o livro também utiliza fontes de outro tipo, como relatos de viagens e documentação cartorária. Vale citar, entre os viajantes, a compilação de Avelino Teixeira da Horta, As viagens do bispo d. Frei Vitoriano Portuense à Guiné e a cristianização dos Reis de Bissau, obra publicada em 1974. O mesmo vale para a compilação de Paul Hair et al., Barbot on Guinea, publicada em 1992. No caso da documentação cartorial, valeram-se das fontes depositadas no Gemeente Archief, em Amsterdã, que detalham, em muitos casos, as atividades comerciais dos judeus portugueses na África. A importância deste último arquivo confirma, por si só, o papel chave da comunidade judaica estabelecida na Holanda para o funcionamento das redes sefarditas no comércio mundial, a partir do século XVII.
A matéria é distribuída em seis capítulos muito bem concebidos. $\mathrm{O}$ primeiro trata das origens das comunidades sefarditas na Petite Côte, bem como suas conexões com os judeus portugueses de Amsterdã, todos mercadores de grosso trato. $\mathrm{O}$ segundo trata da identidade construída pelos sefarditas e de suas relações com os demais grupos que viviam na região. $\mathrm{O}$ terceiro examina a relação entre os mercadores judeus e as autoridades muçulmanas que, na maioria das vezes, apoiaram os sefarditas e, mais que isso, procuraram defendê-los das investidas do Santo Ofício português. O quarto trata das atividades comerciais: circuitos, valores, rotas, mercadorias. O quinto trata do comércio do marfim e de armas brancas, como espadas e adagas, incursionando também na história da arte, em particular na estatuária. O sexto particulariza o papel dos mercadores judeus de Porto d'Ale e Joala no comércio atlântico, examina o percurso de retorno de vários judeus para Amsterdã e realiza um balanço do legado sefardita na Guiné.

A obra traz novidades que refinam nosso conhecimento, quer sobre a diáspora sefardita na Época Moderna, quer sobre o funcionamento do capitalismo comercial no século XVII. Destaca-se, porém, a contribuição dos autores para o estudo dos "negócios africanos" na costa senegalesa naquele tempo. $\mathrm{O}$ estudo dos sefarditas funciona, portanto, não só como objeto em si mesmo, senão como janela para se compreender as complexas relações entre soberanos 
e chefias dos reinos da Petite Côte e os comerciantes europeus e africanos. Mercadores de variegada procedência e confissão religiosa: judeus, católicos, protestantes e muçulmanos, vindos da Europa, do Magreb ou de outras regiões africanas. Vale ressaltar, a propósito, o primeiro apêndice da obra, no qual encontramos preciosas listas nominativas. A primeira oferece uma personalia de cerca de quarenta nomes de comerciantes judeus atuantes em Porto d'Ale e Joala, seus parentes e parceiros cristãos-novos, desde 1606 até 1635 . A segunda apresenta uma lista dos residentes naqueles portos na fase inicial da presença sefardita, conforme o relato de João Mendes (1612): oito viviam em Joala e nove em Porto d'Ale. A terceira oferece dez nomes de comerciantes especializados no comércio de espadas e adagas, que compravam as armas em Lisboa (dos "espadeiros" ou "barbeiros de espadas") para vendêlas na costa guineense. Nunca será demais realçar o valor dessas listas para futuros pesquisadores das redes sefarditas ou do comércio na costa senegalesa durante o século XVII.

$\mathrm{O}$ estudo também contribui para relativizar o papel dos mercadores judeus no tráfico de escravos, sem chegar, obviamente, a desmerecê-lo. O balanço dos negócios sefarditas na região, no período estudado, comprova que a atuação dos judeus no tráfico foi marginal, se comparada a seu engajamento em outros negócios. Mas os autores cuidam de advertir que a Petite Côte não era a principal área da costa guineense engajada no tráfico negreiro.

Em todo caso, a importância da feitoria portuguesa de Cacheu, fundada em 1588, na atual Guiné-Bissau, poderia sugerir um peso maior dos judeus e cristãos novos no tráfico de escravos. Os autores reconhecem a importância de Cacheu para os sefarditas, sobretudo como lugar de passagem e de comércio eventual de outras mercadorias, nem tanto como local de residência. Terá sido em razão de ter se estabelecido em Cacheu um vicariato com foro inquisitorial? Possivelmente. Na feitoria de São Jorge da Mina, ou Elmina, porém, a presença dos sefarditas é bem conhecida. Isto não contraria a interpretação dos autores, pois Elmina ficava na Costa do Ouro, atual Gana, e não na Petite Côte. Além disso, a feitoria foi tomada pelos holandeses em $1637 \mathrm{e}$, como é sabido, os batavos eram tolerantes com os judeus.

O que dizer, porém, do forte de Bezeguiche, na ilha Goréia, localizado defronte a Dacar e muito próxima a Rufisqui, na Petite Côte, onde havia importante comunidade sefardita? Ali o tráfico de escravos assumiu enorme importância desde cedo. Nossos autores esclarecem, porém, que houve perseguição aos judeus, não somente na Goréia, como em Cacheu, por volta de 1629, por ocasião da expedição comandada pelo governador João Pereira Corte Real. Foi neste ano que a "sinagoga" de Rufisqui foi fechada.

Seja como for, os sefarditas puderam respirar com alguma tranqui- 
lidade na Petite Côte, porque os anfitriões muçulmanos lhes deram eficiente proteção. No Marrocos não foi diferente, bem como no império otomano, que era turco, mas também islâmico. No caso africano, as chefias muçulmanas abrigavam mercadores estrangeiros por tradição, fossem africanos de outras partes, fossem judeus. No caso dos últimos, isto foi ainda reforçado pelo sentimento anticatólico. A rejeição dos sefarditas às imagens e rituais católicos favoreceu a aproximação entre os dois grupos confessionais. Aproximação semelhante ocorreu, aliás, na própria Holanda, entre judeus e calvinistas, unidos na crítica ao "papismo" e à "idolatria" católica.

Mark e Horta sugerem, ainda, que os judeus luso-africanos, incluindo obviamente os mestiços, cultivaram algum sincretismo religioso, favorecido, no caso, pela distância em relação aos centros rigoristas do sefardismo na Europa. Baseados na crônica de um francês, Nicolas Villault, Relation des costes d'Afrique appelées Guinée (1669), sugerem que certas orações judaicas que invocavam Abraão, Isaque e Jacó, possuíam alguma coisa de paganismo. A meu ver, a evidência deste sincretismo é modesta para sustentar uma "interação religiosa" ou fusão de crenças judaico-pagão. Entre africanos adeptos de cultos pagãos e portugueses católicos, sim, tal interação é claramente comprovada. A obra de John Thornton, Africa and the Africans in the Making of the Atlantic World (1992) oferece provas inequí- vocas da gênese de um "catolicismo africano" no reino do Congo, que vale também para Angola - regiões de povos bantos. Mas entre judeus e africanos pagãos, o presumido sincretismo precisaria de evidências mais consistentes.

Outra controvérsia diz respeito a se houve ou não racismo dos sefarditas em relação aos mulatos e negros. Mark e Horta tendem a confirmar a opinião de Jonathan Schorsch, em Jews and Blacks in the Early Modern World (2004), para quem é possível verificar preconceitos raciais contra os negros desde o início do século XVII. Schorsch rejeita, com razão, a ideia de que o racismo, no sentido moderno, seja resultado da Ilustração no século XVIII. Nossos autores sugerem, porém, que as atitudes dos judeus em face dos negros, em especial aos mestiços ou mulatos integrantes da comunidade judaica, eram amiúde contraditórias, ora preconceituosas, ora tolerantes. Os sefarditas que retornaram de Petite Côte para Amsterdã, segundo os autores, exprimiam uma opinião bastante positiva em relação aos judeus de "pele escura", ao menos na primeira metade do século XVII. Interpretação similar foi sustentada por Tobias Green em "Amsterdam and the African Atlantic" (2008), que descreveu os sefarditas da Petite Côte como uma "comunidade aberta", que floresceu na África subsaariana e manteve forte ligação com seus anfitriões africanos.

Mark e Horta são cautelosos neste ponto, reconhecendo que as restri- 
ções legais aos judeus "euro-africanos" impostas pela comunidade sefardita de Amsterdã datam, quando menos, da década de 1640 . Os autores registram a discriminação, mas admitem que a simples existência dessa legislação pode indicar a possível ascensão social dos judeus "euro-africanos" entre os sefarditas. Insistem, porém, no caráter errático e ambíguo das discriminações do conselho judaico, a exemplo da autorização ou proibição do enterramento dos "judeus de cor" no cemitério de Ouderkerk: em 1627, os judeus euroafricanos tinham que ser enterrados fora do cemitério; em 1647 esta interdição foi suspensa em relação aos mestiços de "judeus pretos com brancos"; em 1682, os judeus mulatos ganharam uma área separada dentro do próprio cemitério. $\mathrm{O}$ modo de discriminar muda ao longo do tempo, mas permanece algum tipo de discriminação.

Trata-se de questão relevantíssima, sem dúvida, mas penso que ela não pode ser analisada apenas em função dos judeus egressos da Petite Côte, cujo peso na comunidade sefardita era decerto menor do que os provenientes de Portugal ou das comunidades sefarditas mais antigas do Mediterrâneo. No conjunto, baseado nas informações de Yosef Kaplan (Judios Nuevos en Amsterdam, 1996), diria que, mais cedo do que tarde, as congregações judaicas tenderam a discriminar os judeus mulatos, o que só fez aumentar após a unificação delas na Talmud Torá, em 1639. Em
Jerusalém Colonial (2010), examinando as normas (askamot) da Zur Israel aprovadas em 1648, constatei uma forte discriminação dos negros e mulatos. O regulamento proibia a circuncisão de escravos, mesmo que os senhores os libertassem. O problema não residia na condição escrava, mas na cor negra ou na origem africana.

Por outro lado, o exclusivismo identitário dos sefarditas de Amsterdã não dizia respeito apenas aos judeus “euro-africanos”. Estendia-se, talvez em maior escala, aos judeus provenientes da Europa centro-oriental, os ashekenazim, a partir da década de 1640. A legislação da Talmud Torá era duríssima com os judeus "polacos e tudescos", do mesmo modo que o era com os mulatos. $\mathrm{O}$ iberismo dos sefarditas e, mais que isto, sua insegurança identitária, pois muitos tinham sido criados no catolicismo e mal conheciam o judaísmo, são elementos essenciais para se compreender a intolerância "racial" do conselho judaico (mahamad).

$\mathrm{O}$ aspecto mais polêmico do livro reside, porém, nada menos do que na sua tese central, ou seja, que nas comunidades sefarditas da Petite Cotê erigiu-se uma comunidade judaica observante das tradições sefarditas (ainda que metamorfoseadas), abrangendo a tradição oral, a observância dos ritos domésticos e, sobretudo, alguma estrutura sinagogal.

É verdade que Mark e Horta apresentam dados inéditos sobre o funcionamento de uma sinagoga em 
Joala, na casa de Diogo Vaz de Sousa, o velho, e de outra em Porto d'Ale, cujas cerimônias eram oficiadas pelo rabino Jacob Peregrino. Informam sobre o papel de seu filho, Manuel Peregrino, que também atuou como mohel (circuncisador). Reúnem diversas evidências, extraídas sobretudo das fontes inquisitoriais, sobre a observância de cerimônias, circuncisões, orações etc. No entanto, não chegou a existir nenhuma congregação sefardita na Petite Côte, a exemplo do que ocorreria no Brasil holandês, a partir de 1636, ou das comunidades judaicas do Caribe, na segunda metade do século XVII.

As informações sobre as práticas judaicas na costa senegalesa são, comparativamente, muito escassas e não provêm de fontes da própria comunidade, salvo lateralmente. Boa parte das evidências lembra mais o criptojudaísmo do que o sefardismo sinagogal estruturado em outras diásporas da mesma época. A documentação não detalha as festas, o uso do tallet e das tefillot pelos yahidim. Há menção a doze cópias da Torá levadas à Petite Côte por Jacob Peregrino, que nossos autores esclarecem, a tempo, que não passavam de livros de orações, possivelmente extraídas da Bíblia de Ferrara (em castelhano), como as usadas em Amsterdã ou no Recife. Mas, à diferença dos documentos sobre outras congregações sefarditas da época, quer judaicos, quer inquisitoriais, não há detalhes sobre elas. Também as considerações sobre a "colher de marfim" enquanto "ponteiro" para a leitura da Torá, me pareceram especulativas. Os próprios autores questionam, a certa altura, se Jacob Peregrino era mesmo um "rabino" ou um guia espiritual dos sefarditas residentes na Petite Côte. De fato, não há documentos que o designem como haham, senão como "rabbi" ou "doutor rabi", o que faz muita diferença. Em resumo, o sefardismo da Petite Côte parece não ter se organizado institucionalmente, pois não há menção às askamot, quer em Joala, quer em Poro d'Ale, muito menos em Rufisqui.

Em todo caso, as críticas que venho de fazer em nada empalidecem o valor da pesquisa e do livro que dela resultou. Os autores provam, isto sim, a existência de uma comunidade sefardita na Petite Côte que ocupava, a meu ver, uma posição intermédia entre as congregações sefarditas de Amsterdã, Recife ou Hamburgo e o criptojudaísmo típico do mundo ibérico vigiado pelo Santo Ofício.

Seja como for, se o melhor que pode oferecer um livro de história é a ampliação do conhecimento sobre o tema escolhido, a renovação do objeto, o ineditismo das fontes e a ousadia das interpretações, a obra de Mark e Horta cumpre à farta o seu papel. Uma contribuição inestimável à bibliografia sobre o sefardismo, o capitalismo comercial e as sociedades da costa senegalesa no século XVII.

Ronaldo Vainfas

rvainfas@terra.com.br

Universidade Federal Fluminense 